\title{
Physical environment and hygiene status at food service establishments in a tertiary care medical college campus in Delhi: A cross-sectional study
}

\author{
Pallavi Boro', Vishal C. Soyam², Tanu Anand ${ }^{3}$, Jugal Kishore ${ }^{4}$ \\ ${ }^{1} 3^{\text {rd }}$ Year PG Student, Department of Community Medicine, Maulana Azad Medical College and Associated, L.N. Hospitals, New Delhi, \\ ${ }^{2}$ Assistant Professor, Department of Community Medicine, MVJ Medical College and Research Hospital, Bangalore, ${ }^{3}$ Senior Resident, \\ Department of Community Medicine, Maulana Azad Medical College and Associated, L.N. Hospitals, New Delhi, ${ }^{4}$ Professor, Department of \\ Community Medicine, Maulana Azad Medical College and Associated, L.N. Hospitals, New Delhi
}

\section{A B S T R A C T}

Introduction: Food can be a potential source of infection and disease, right from the point of preparation to the point of consumption. It is more likely in the food service establishments where mass food is prepared. Objectives: To study the physical environment and hygiene status at food service establishments in a tertiary care teaching hospital in central Delhi. Methods: An observational cross sectional study was conducted from June-August, 2014 in medical college and associated hospital in Delhi using questionnaire to assess sanitation and environmental hygiene status. The checklist contained 12 categories with a maximum possible score of 139 for the vegetarian and 140 for the non-vegetarian food establishments. The classification of the establishments on the basis of score obtained is as follows: Grade $1=0-25 \%$, Grade $2=26-50 \%$, Grade $3=51-75 \%$, Grade $4=76-100 \%$. Data analysis: The data was analyzed using SPSS version 20. Results: A total 13 food service establishments were included of which most (92.3\%) were operated on contractual basis. Majority (84.6\%) provided non-vegetarian food. None of the food handlers were given uniform to wear during their working hours. Few $(15.2 \%)$ were using caps but those were not covering the entire hair. Conclusion: The conditions of the food establishments in the medical college campus are not of prescribed standard and needs improvement.

Key words: Food service establishment, Sanitation, Hygienic practices, Food handlers

\section{INTRODUCTION}

Food can be a potential source of infection and disease, right from the point of procurement to the point of consumption. It is more likely in the food service establishments where mass food is prepared. Hygienic practices at procuring, preparing and serving are essential. Food handlers specially play a major role here. ${ }^{1}$ Epidemiological and surveillance data suggest that faulty practices in food processing plants, food service establishments and home play a crucial role in the causal chain of food-borne diseases. ${ }^{2}$

Study in the USA indicated that improper food handling practices contribute to $97 \%$ of food borne illness in food service establishments and at home. ${ }^{3}$ In England and Wales, the majority of cases, about $58 \%$, were associated with food prepared and served in food establishments. ${ }^{4}$

Lack of basic infrastructure, under staffing, lack of knowledge of hygiene, absence of potable water, use of unhygienic material, not keeping food at safe temperature, lack of proper storage facility and unsuitable environments for food operations (such as proximity to sewers and garbage dumps) can contribute to outbreaks of food borne illnesses. Inadequate facilities for garbage disposal posed further hazards. ${ }^{5}$ In addition poor sanitary practices in food storage, handling, and preparation can create an environment in which bacteria and other infectious agents easily grow, multiply and transmit. ${ }^{6,7}$ 
The food born diseases are a major public health problem, with time to time outbreaks taking high death toll. Developing countries are more at risk of these because of not only faulty food handling practices, or presence of vast number of food borne pathogens, but added burden of inadequate supply of safe drinking water and poor environmental sanitation. According to WHO report 2000 , an estimated $70 \%$ of cases of diarrheal disease are associated with the consumption of contaminated food in developing countries. ${ }^{8}$ Between 1998 and 2004, an average of 9040 food borne disease outbreaks were reported to the Centre for Disease Control and Prevention (CDC). Approximately 4675 (52\%) of these were attributed to food service establishments. ${ }^{9}$ To control and prevent food borne diseases, food hygiene is a must, which comprise of hygienic practices of the food handlers and hygienic environment at the food establishments. ${ }^{10}$

In a medical college cum hospital campus where presence of sick people in different age groups, and numerous pathogens often make an unclean surrounding, the food serving points can turn as a potential source of infection very easily. Moreover vulnerability to food-borne diseases is increased as immune system is compromised by different diseases including HIV infection; and malignancy and immunosuppressive treatments. ${ }^{11}$

Since medical institutions are supposed to provide a model for healthy practices, including food services, it is expected that the food service establishments there should not act as source of infection for food-borne diseases. However, a number of outbreaks of food borne illnesses have been reported from the different medical college hostels from time to time resulting in illness and hospitalization of medical students and doctors. Any incidence of food born diseases that affect medical students and doctors can result not only in sickness absenteeism but also in ease of transmission of pathogen to patients and their relatives which ultimately affect the health care services to a great extent. This explains the importance of maintaining high food safety levels at food establishments in medical colleges and hospital campus.

Therefore this study was planned with an objective to study the physical environment and hygienic status of the food service establishments in a medical college and associated tertiary care Hospital in central Delhi.

\section{MATERIALS AND METHODS}

\section{Study design, setting}

An observational cross sectional study was carried out at various food service establishments located within the premises of a medical college and associated tertiary care hospital in central Delhi. Total of 13 food serving establishments were included.

\section{Food service establishment}

Is a place where food is prepared and intended for individual portion service and includes the site at which the individual portions are provided, whether consumption occurs on or off the premises. ${ }^{12}$

In the current study the food service establishment included all the food outlets inside the campus having a pre-constructed site from where the doctors, staffs, patients and their attendants can consume food.

The data collection was done over a period of three months from June to August, 2014.

All the food serving establishments were included in the study irrespective of their licensing and registration status.

\section{Study instrument}

The study instrument consisted of the questionnaire and checklist prepared on the basis of the standards and guidelines drawn by Bureau of Indian Standards (BIS), ${ }^{13,14}$ Municipal Corporation Department (MCD) ${ }^{15}$ and world health organization (WHO) ${ }^{16-18}$ It included items like nature of the floor; roof; walls; doors, windows and presence or absence of other infrastructure. It also included type of establishments, sanitary facilities, food storage, fruit and vegetable washing and cutting practices and the personal hygiene of food handlers. Practices such as handling of food, place of preparation of food, methods of washing utensils and preservation methods of food were studied. The establishments were also assessed for sanitary practices such as availability of wash basin, running water, soap, towels and disposal of waste. Privacy and confidentiality of data was maintained at all stages of the study.

\section{Data collection}

Canteens and messes were taken as a study unit. The investigating team consisted of one male and one female investigator who visited the study site during their peak working hour. The hygienic status of food service establishment and the activities of food handlers at work recorded, without drawing attention of workers and the customer around. The food serving area, kitchen, raw food storage area and rest room area for the canteen staff, if present were visited and assessed in terms of cleanliness and availability of desired facilities and were given the scores accordingly. The team also interviewed the manager regarding time of serving, licensing/ registration, information about staff, type of food served etc. Each item consisted of 2 or more options which 
were assigned with score of 0,1 or 2 depending upon the satisfaction level. The total checklist contained 12 categories with a maximum possible score of 139 for the vegetarian and 140 for the non-vegetarian food serving establishments. The classification of the establishments on the basis of score obtained was graded as follows: Grade $1=0-25 \%$, Grade $2=26-50 \%$, Grade 3 $=51-75 \%$, Grade $4=76-100 \%$.

The data was analyzed using MS Excel and SPSS version 20. Results were expressed in mean + SD or proportion wherever relevant.

\section{RESULTS}

A total of 13 food service establishments functioning within the premises were included in the study. They served 40 to 750 customers (Median - 288) per day. These establishments included 7 hostel messes and 6 canteens. Among these establishments, $12(92.3 \%)$ were operated by private contractors and $1(7.7 \%)$ was by the government. Approximately $2 / 3^{\text {rd }}$ of establishments had license issued by MCD for food service establishments that had to be renewed on an annual basis. Two establishments used to provide services all seven days a week for 24 hours and 11 were providing from $7 \mathrm{am}$ to $11 \mathrm{pm}$ only. The median years of service of the establishments were 4 years, ranging from two months to forty-eight years. Five operators had been running the establishment for more than five years and four for more than one year and the rest for less than a year. Six of the managers were formally trained. Eleven (84.6\%) establishments served both vegetarian and non-vegetarian food. All the establishments provided breakfast, lunch and dinner with snacks, except two which were not providing the evening tea/snacks and dinner.

The physical environmental condition of food service establishments was assessed for both dining and kitchen area as shown in Table 1. There was no provision for separate washbasin for washing of hands in kitchen area other than those used for cleaning utensils in 4 establishments. Exhaust fans were present and all were in working condition in the kitchen areas of all the establishments but majorities $(91.7 \%)$ were not clean.

In the dining area, the table-chair and the wash basins were found clean in all the establishments.

Soap was present in all except one establishment; there was no facility to dry hands near washbasin, except towel at one place. There was provision of piped water supply in all establishments, water coolers were present in all, but only $7(63.6 \%)$ of them used to cleaned these water coolers at regular monthly interval.
Table 2 explains the hygienic practices in kitchen area which were not satisfactory such as dirty exhaust fans, soap availability in only $2 / 3^{\text {rd }}$ of kitchens, no display of poster/ notice regarding hygiene, non usage of hot water and use of cloth for drying dishes with dishes kept on the floor.

Figure 1 explains the hygienic practices of food handlers; only few establishments' food handlers were using caps

\begin{tabular}{lcc} 
Table 1: The physical environmental condition \\
of food service establishments (N=13) \\
\hline Characteristics & \multicolumn{2}{c}{ Number (\%) } \\
\cline { 2 - 3 } & $\begin{array}{c}\text { Dining } \\
\text { area }\end{array}$ & $\begin{array}{c}\text { Kitchen } \\
\text { area }\end{array}$ \\
\hline Dining area & & \\
Wall - & $3(23.1)$ & $4(30.8)$ \\
Cracks/crevices present & $11(84.6)$ & $11(84.6)$ \\
Washable surface present & & \\
Floor - & $12(92.3)$ & $12(92.3)$ \\
Impervious & $0(0.0)$ & $2(15.4)$ \\
Cracks/crevices present & $5(38.5)$ & $4(30.8)$ \\
Vacuum cleaning & & \\
Ceiling - & $3(23.1)$ & $4(30.8)$ \\
Cracks present & $8(61.5)$ & $6(46.2)$ \\
Flaking present & $7(53.8)$ & $4(30.8)$ \\
Spider web present & $5(38.5)$ & $3(23.1)$ \\
Windows fly screening present & $6(46.2)$ & $1(7.7)$ \\
Door fly screening present & $13(100)$ & $13(100.0)$ \\
Adequate lighting & $12(92.3)$ & $10(76.9)$ \\
Wash basin present &
\end{tabular}

\begin{tabular}{lc}
$\begin{array}{l}\text { Table 2: Hygienic practices observed in kitchen } \\
\text { area (N=13) }\end{array}$ & $\begin{array}{c}\text { Number of } \\
\text { establishments (\%) }\end{array}$ \\
\hline Hygienic practices in kitchen & $8(80.0)$ \\
\hline Soap available at washbasin & $0(0.0)$ \\
Means available for drying hand & $0(0.0)$ \\
Poster/notices displayed regarding hygiene & $9(81.8)$ \\
Satisfactory storage inside refrigerator & $9(81.8)$ \\
Regular cleaning of refrigerator & $9(69.2)$ \\
Dishes washed in sink & $9(69.2)$ \\
Sink cleaned & $6(46.2)$ \\
Hot water used & $10(76.9)$ \\
Dishes washed using water+detergent & $5(38.5)$ \\
Air drying of dishes & $7(53.8)$ \\
Dishes stacked in racks &
\end{tabular}

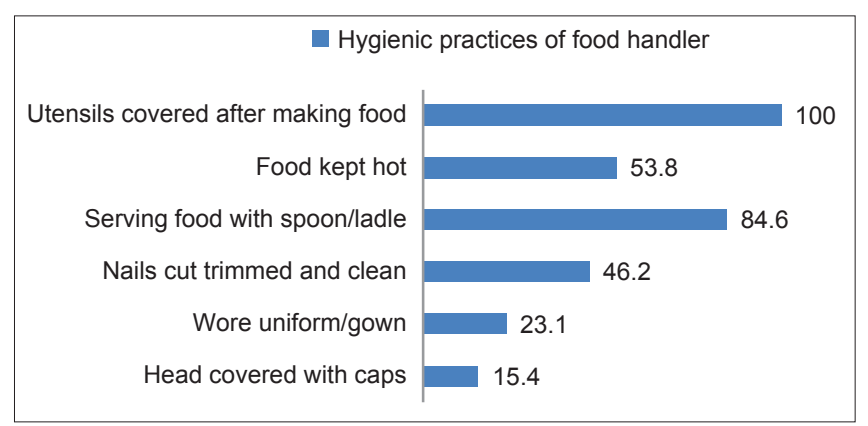

Figure 1: Hygienic practices observed among food handlers 
$(15.4 \%)$ and were in uniform (23.1\%). The food handlers of half of establishments have kept their nails trimmed and cleaned.

All establishments had piped water supply from MCD and all were using water purifier for providing clean water to their customers. The drainage of water at washbasin in dining $(76.9 \%)$ and kitchen area $(61.5 \%)$ of establishments were found to be proper. Toilet and latrine facility were available in 10 (83.3\%) establishments, of which 7 (70.0\%) establishments had washbasin in toilet room. Only three establishments had covered dustbin in kitchen. All the establishments dispose their solid and liquid waste daily in nearby Dhalao of MCD. The cockroaches, rodents and pet/stray animals were not found in dining area of all the establishments; however flies were present in dining area of two establishments, while rodents were observed in one establishment.

Table 3 shows the grading of an establishment on the basis of score allotted, 12 establishments were in grade III and one each in the grade II and grade IV of the hygiene status. It reflects that hygienic status of food service establishments was not satisfactory.

\section{DISCUSSION}

This study assessed hygienic condition of food service establishment in a tertiary care teaching medical college and hospital. There is need to ensure hygienic food handling and preparation practices in such establishments to safeguard the health and well being of medical students, doctors and other paramedical staff and patients with their attendants.

In the present study food service establishments operated by private contractors were more than the study conducted by Malhotra $\mathrm{R}$ et al in the same setting 10 years back, the probable reason could be because of increased privatization in recent years. ${ }^{19}$ Licensing status was also found to be higher than the past. ${ }^{19}$ The disposal of solid waste by Municipal Refuse Collection on a daily basis was the method of waste disposal similar to the findings of a study conducted in Mekelle town of Ethiopia during 2004-2005..$^{20}$ The number of customer served per day were

\begin{tabular}{lccc}
\multicolumn{4}{l}{ Table 3: Status of hygiene of the food service } \\
establishments $(\mathrm{N}=13)$
\end{tabular}

also found similar to Malhotra et al study ranging from 40 to $750($ median $=258) \cdot{ }^{19}$

The presence of cracks on the walls with flaking and spider webs on the ceilings can be explained owing to lack of regular inspection from health authorities and very old buildings which need maintenance. Window and door fly screening has importance in preventing food borne diseases but it was missing in most establishments dining as well as kitchen area. Study from rural area of western Maharashtra showed lower (16\%) proportion of fly-proof premises as compared to our study $(38 \%) .{ }^{21}$ Wash basin with soap was observed in majority of establishments dining (91.7\%) and kitchen $(83.3 \%)$ area, whereas, difference was observed in study from Maharashtra (40.0\%) and Mekelle town of North Ethiopia (57.1\%) because of difference in setting and study area..$^{20,21}$

Present study revealed that all the food establishments had adequate lighting, ventilation with exhaust fan in working condition whereas ventilation was found adequate in only $64.0 \%$ of establishments in rural Maharastra. ${ }^{21}$

None of the establishments displayed posters/notices regarding hygiene and none was kept means for drying hands for cooks in the kitchen. One of the most widely used and accepted methods of washing food utensils was three compartment sink or vat system. Two third establishments used to wash dishes in the sink, of which only two $(16.7 \%)$ were using three sink method, whereas $(46.0 \%)$ of establishments used three sinks in North Ethiopia. ${ }^{20}$ Most of the workers were not using caps $(83.3 \%)$ and uniform/apron $(75.0 \%)$ in kitchen and dining area. Similar to present research, apron and caps were not used by most of the food handlers $(84.5 \%)$ in a research done by Ansari MA et al in medical college setting of Aligarh. ${ }^{22}$ Other researchers from Solapur district of Maharastra and Ghana also reported similar findings. ${ }^{23,24}$ Food handlers from Ghana, Aligarh and Mekelle Town showed higher proportion of food handler with trimmed nails i.e. $63.3 \%, 69.9 \%$ and $76.2 \%$ respectivelywhile only half of the food handlers had cleaned and trimmed nails in the present study. ${ }^{20,22,24}$

The utensils were covered in all the establishments after food was prepared, although half of them had the facility to keep food hot. Majority (83.3\%) dished out food with ladle while few served through bowls or bare hands; this differs from findings reported by Monney in Ghana that all food handlers dish out food with ladle/spoon. ${ }^{24}$

Poor sanitary condition is responsible for rapid growth and easy transmission of bacteria and other infectious agents. ${ }^{6}$ Two establishments did not had toilet and latrine facility 
for the employees. The percentage of establishments with toilet facilities in Mekelle (97\%), in Awassa (95\%) and in Addis Ababa (86\%) was higher than that observed in our study. ${ }^{20,25,26}$ Only three (25.0\%) establishments had covered dust bin and investigator also found garbage was present outside bin in two establishments. These practices were unsanitary as they are prone to spillage and serve as good breeding grounds for flies. Two different studies conducted in Ethiopia revealed inadequate sanitary facility with improper waste management as common features of catering establishments. ${ }^{5,27}$

\section{CONCLUSION \& RECOMMENDATION}

There are certain standards and norms set by WHO and MCD that should be followed by any food service establishments, but these are often not practiced and maintained. This is due to ignorance and lack of motivation from food providers' point of view, due to non sensitive attitude and lack of awareness regarding food born diseases, and lack of mandatory enforcement and supportive supervision from higher authorities' point of view. Whatever may be the hindering cause, it is now the time to address these issues to improve the hygienic status of the food serving establishments and to reduce burden of easily preventable food borne diseases.

Although the conditions of the food establishments in the medical college campus was satisfactory, there is scope for further improvements in every area seen, such as infrastructure, hygiene and sanitary practices etc. The buildings need to be maintained, supervision/inspection from higher health authority at regular interval is required. Proper dress code with apron and head cap should be made compulsory for food handlers. All the establishments should get license at the earliest. Measures should be taken to improve the environmental sanitation status of food establishments in medical college hospitals. There is need to give proper training and appropriate protective wear to food handlers. Building infrastructure should be maintained and supervisory visits from higher authorities at regular interval should be enforced.

\section{ACKNOWLEDGEMENT}

Establishment owners/managers and food handlers are appreciated for their interest and full participation in the study.

\section{REFERENCES}

1. Adams $M$ and Motarjemi $Y$. Basic food safety for health workers. WHO, Geneva, 1999 http://whqlibdoc.who.int/hq/1999/WHO_ SDE_PHE_FOS_99.1.pdf Retrieved 24/08/2014, 10,12hrs.
2. Prabhu PM and Shah RS. A Study of Food Handlers in Public Food Establishments in Maharashtra, India. International Journal of Science and Research 2012; 1485-1489.

3. Howes M, McEwen S, Griffiths M and Harris L. Food handler certification by home study: Measuring changes in knowledge and behavior. Dairy Food and Environmental Sanitation 1996; 16(7):737-744.

4. Hobbs BC and Diane R. Food Poisoning and Food Hygiene. London: Hodder Arnold;1987.

5. Kibret $M$ and Abera $B$. The sanitary conditions of food service establishments and food safety knowledge and practices of food handlers in Bahir Dar Town. Ethiop J Health Sci 2012; 22(1):27-35.

6. Fielding JE, Aguirre A and Palaiologos E. Electiveness of altered incentives in a food safety inspection program. Prev Med 2001; 32: 239-244.

7. Gent RN, Telford DR and Syed Q. An outbreak of Camphylobacter food poisoning at a university campus. Commun Dis Public Health 1999; 2:39-42.

8. World Health Organization. Food borne Disease: A focus for Health Education. WHO, Geneva. 2000.

9. CentersforDiseaseControlandPrevention. UnitedStatesfoodborne disease outbreaks. Centers for Disease Control and Prevention (Atlanta) 2006. http://www.cdc.gov/foodborneoutbreaks/outbreak_ data.htm Retrieved 10/07/2014, 12,30 hrs.

10. Murat B, Azmi S, Ersun and Gokhan K. The evaluation of food hygiene, knowledge, attitudes, and practices of food handlers in food businesses in Turkey. Food Control 2006; 17:317-322.

11. Van de Venter T. Emerging Food-borne Diseases: a global responsibility. FAO corporate document repository, 2009. http:// www.fao.org/docrep/003/X7133M/x7133m02.htm Retrieved 08/07/2014, 12,32hrs.

12. Health and safety in the home, workplace and outdoors [Serial Online]. 2014 [Cited 2014 Aug 20]: https://www.health. ny.gov/regulations/nycrr/title_10/part_14/subpart_14-1.htm\#s20 Retrieved 18/08/2014, 12,32hrs.

13. IS: $6074-1971$. Indian standard: code for functional requirements of hotels, restaurants and other food service establishments. Indian Standards Institution. New Delhi. 1971. https://law. resource.org/pub/in/bis/S03/is.6074.1971.pdf Retrieved 20/06/2014, 12,32hrs.

14. IS: 2491:1998. Indian standard: food hygiene-general principles- Code of practice (second Revision). Bureau of Indian standards (BIS), New Delhi. 1998. https://law.resource.org/pub/ in/bis/S06/is.2491.1998.pdf Retrieved 20/06/2014, 12,32hrs.

15. Technical instructions and Bye-Laws for Trade Licenses. Health department, Municipal Corporation of Delhi.

16. Jacob M. Safe food handling: A training guide for managers of food service establishments. WHO, Geneva 1989.

17. Health surveillance and management procedures for foodhandling personnel. Report of WHO consultation. WHO technical Report Series, No. 785, 1989.

18. Hygiene in food service and mass catering establishments, important rules. WHO/FNU/FOS/94.5. WHO, Geneva 1994.

19. Malhotra R, Lal P, Prakash SK, Daga MK and Kishore J. Profile of food handlers working in food service establishments located within the premises of a medical college in Delhi, India. Public Health 2007;121(6):455-461.

20. Zeru K and Kumie A. Sanitary conditions of food establishments in Mekelle town, Tigray, north Ethiopia. Ethiop J Health Dev 2007; 21:3-11.

21. Deshpande JD and Phalke DB. The sanitary condition of food establishments and health status and personal hygiene among food handlers in a rural area of Western Maharashtra, India. Asian Journal of Medical Sciences 2013; 4(2):23-29. 
22. Ansari MA and Khan Z. An Evaluation of Health Education Intervention on Hygienic Status of Food Handlers in Aligarh - A Three Year Experience. J Community Med Health Educ 2012; 2:142. doi:10.4172/2161-0711.1000142

23. Takalkar AA and Kumavat AP. Assessment of personal hygiene of canteen workers of government medical college and hospital, Solapur. National Journal of Community Medicine 2011; 2 (3): 448-451.

24. Monney I, Agyei D and Owusu W. Hygienic Practices among Food Vendors in Educational Institutions in Ghana: The Case of Konongo Foods 2013; 2: 282-294.
25. Shiferaw TM, Belay R, Solomon S, Solomon W and Loipiso E. Assessment of sanitary and hygienic status of catering establishments of Awassa town. Ethiopia $\mathrm{J}$ Health Dev 1999;14(1):91-98.

26. Fisseha G. Berhane Y. and Teka GE. Public Catering Establishments in Addis Ababa: Physical and Sanitary Facilities. Ethiop J Health Dev1999; 13(2):127-134.

27. Kumie A, Genete K, Worku H, Kebede E, Ayele F and Mulugeta H. The sanitary conditions of public food and drink establishments in the District town of Zeway, Southern Ethiopia. Ethiop J Health Dev 2002; 16(1):95-104.

\footnotetext{
Authors Contribution:

PB - designed the study, Data collection, analysed the data, drafted the manuscript, \& reviewed the manuscript; VS - Contributed to the study design, Data collection and data analysis; TA - Data collected and Reviewed the manuscript; JK - Contributed to the study design and review the manuscript.

Source of Support: Nil, Conflict of Interest: None declared.
} 